To cite this article: Hibai Lopez-Gonzalez, Ana Estévez \& Mark D. Griffiths (2017): Controlling the illusion of control: a grounded theory of sports betting advertising in the UK, International Gambling Studies, DOI: 10.1080/14459795.2017.1377747

To link to this article: http://dx.doi.org/10.1080/14459795.2017.1377747

\title{
Controlling the illusion of control: A grounded theory of sports betting advertising in the UK
}

\begin{abstract}
Sports betting (SB) advertising has arguably permeated contemporary sport consumption in many countries. SB adverts build narratives that represent situations and characters that normalise betting behaviour, and raise public concerns regarding their detrimental effect on vulnerable groups. Adopting a grounded theory approach, the present study examined a British sample of SB adverts ( $\mathrm{N}=102)$ from 2014 to 2016. The analysis revealed that individual themes aligned in a single core narrative, constructing a dual persuasive strategy of SB advertising: (i) to reduce the perceived risk involved in betting (with themes such as betting with betting with friends, free money offers, humour, or the use of celebrities) while (ii) enhancing the perceived control of bettors (including themes of masculinity, and sport knowledge). Also, new technological features of SB platforms (e.g. live betting or cash outs) were used by adverts to build a narrative in which the ability to predict a sport outcome was overlapped by the ability of bettors to use those platforms, equalising the ease of betting with the ease of winning. Based on the data analysed, it is concluded that the construction of a magnified idea of control in SB advertising is a cause for concern requiring close regulatory scrutiny.
\end{abstract}

\section{Background}

Gambling advertising has been widely considered a situational stimulus that, if transmitted irresponsibly, may contribute to gambling problems (Griffiths, 2005; Hanss, Mentzoni, Griffiths, \& Pallesen, 2015). Although the causal mechanism is not clear (Binde, 2014a, 2014b), one of the paths of gambling advertising influence could be via narratives that represent situations and characters that gamblers can empathise with, and which promote and naturalise specific behaviours while underrepresenting others (Hirschman, 1988; Milner \& Nuske, 2012). In the case of sport, sports betting (SB) advertising appears to be aligning with pre-existing attitudes and cognitions about sport and sportspeople (Deans, Thomas, Daube, \& Derevensky, 2017; Deans, Thomas, Daube, Derevensky, \& Gordon, 2016; Gordon, Gurrieri, \& Chapman, 2015; Hing, Vitartas, \& Lamont, 2014; Thomas et al., 2015; Thomas, Lewis, Duong, 
\& McLeod, 2012). Such attitudes and cognitions are far from neutral because for may sports fans, sport content consumption is often an emotionally charged activity (Crawford, 2004). Given this, it is unsurprising that the content and narratives of SB commercial messages has attracted scrutiny from consumers and regulators (Lopez-Gonzalez, Estévez, \& Griffiths, 2017), seconded by research indicating that more severe problem gamblers report higher subjective influence of gambling promotions on their SB behaviour (Hing, Russell, Lamont, \& Vitartas, 2017).

European gambling advertising regulation took centre stage after the legalisation of online gambling in most countries from mid-200os to early 2010s. Although each member state of the European Union (EU) was responsible for their own regulation on gambling, the EU promoted a harmonization process initiated by the Green paper on online gambling (European Commission, 2011). This paper identified commercial communications towards vulnerable groups as one of the six key factors triggering problem gambling and set up a group of experts to inform public policy on this. Such consultations resulted in 2014 in a recommendations document that included provisions to protect consumers from irresponsible marketing (European Commission, 2014).

In the impact assessment document attached to these recommendations, the EU highlighted a series of rules for gambling advertising narratives that included the prohibition of addressing children (e.g., building narratives containing people under 25 years of age; portraying peer pressure to gamble, or presenting gambling as a rite of passage); and limitations to promote messages that encourage irresponsible gambling (e.g., depicting gambling as an alternative to employment, a solution to financial concerns, or the depiction of solitary gambling as preferable). Also, other irresponsible appeals where explicitly banned such as presenting gambling as a form of gaining control or superiority, condoning irresponsible behaviour, depicting gambling as a form of sexual seduction or enhanced attractiveness, and introducing gamblers as representatives of toughness, resilience, and recklessness (European Commission, 2014). These rules were implemented in several EU member states' regulations, including the UK.

Nevertheless, gambling advertising appears to be building its persuasive messages around legitimate narratives. Recent research examining gambling compliance of advertising regulation and codes of conduct has typically found that gambling messages abide by the existing laws (Gainsbury, Delfabbro, King, \& Hing, 2016; Lopez-Gonzalez \& Griffiths, 2016a). However, older studies investigating gambling advertising identified narratives that under current regulatory frameworks in most jurisdictions would be considered illegal. These themes included gambling as a form of social and financial success (Korn, Hurson, \& Reynolds, 2005), retreating from social life (McMullan \& Miller, 2008), the emphasis of luck over hard work, 
and the presentation of gambling as sensible investing (Griffiths, 2005), among other misleading content exploiting irrational beliefs (Monaghan, Derevensky, \& Sklar, 2008).

Content analyses of gambling advertising narratives from different countries conducted under responsible marketing perspectives have resulted in an ever expanding list of themes identified in the adverts that could induce irresponsible gambling such as fun, excitement and entertainment (McMullan \& Miller, 2009), adventure (Thomas et al., 2015), humour (Korn et al., 2005; Sklar \& Derevensky, 2011; Thomas et al., 2015), normalisation of gambling (McMullan \& Miller, 2009), ease of use (Gainsbury et al., 2016), glamour (Gainsbury et al., 2016), aligning gambling and sport (Gainsbury et al., 2016; McMullan \& Miller, 2008; Sklar \& Derevensky, 2011), friendship (Deans, Thomas, Daube, Derevensky, et al., 2016), and masculinity (Sproston, Hanley, Brook, Hing, \& Gainsbury, 2015).

For SB advertising in particular, individual interviews and focus groups have also been utilized to extract narrative themes from gambling adverts. In a recent study interviewing 50 sports bettors, interviewees felt SB advertisements were trying to create a symbolic alignment with sports, particularly targeting young bettors. Also, 'free bet' or 'money-back' narratives promoted the idea of 'insurance types of bets', which produced an enhanced sense of control over the bet while reducing the perceived risk (Deans, Thomas, Derevensky, \& Daube, 2017). In other focus group research with sport bettors, narratives that promoted the perception of SB companies as offering good value for money were systematically seen positively by bettors (Lamont, Hing, \& Vitartas, 2016). In a study involving 59 conversations between parents and adolescent children, mothers rated SB narratives more positively in adverts where families spent time together and the value of connectedness was represented (Thomas, 2014). Sports fans have reported that SB advertising saturates their consumption of televised sport and incentivises their SB behaviour, making it more difficult to ignore it (Thomas, Lewis, McLeod, \& Haycock, 2012). In Australia, for instance, SB advertising in 2012 constituted 2.5\% of air time of typical sports broadcasts (Milner, Hing, Vitartas, \& Lamont, 2013). In contemporary European soccer, with electronic banners around the field almost exclusively devoted to SB brands and shirt sponsorships (Lopez-Gonzalez \& Griffiths, 2016b), the proportion is likely to have grown.

Deans, Thomas, Daube et al. (2016) systematically categorised and gauged narrative themes in SB advertising by creating a coding template of seven broad categories: adventure, gender, peer bonding, patriotism, sexualised imagery, social status, and winning. They later added inductive happiness, power/control, and sports fan rituals. After analysing $85 \mathrm{SB}$ adverts, they concluded that sports fan rituals and behaviours were represented in $78 \%$ of the narratives, with friendship being the second most represented (48\%). Interestingly, the authors argued that social cohesion was misconceived, and that adverts misrepresented gambling as an activity that cannot be harmful if done publicly (Deans et al., 2016). In other 
attempts to categorise SB advertising narratives, scholars have catalogued narratives by the type of inducement they promote, resulting in 15 different categories, although all of them consisted of money-based inducements -e.g. sign-up offers, bonus or better odds, free bets or reduced commissions (Hing, Sproston, Brook, \& Brading, 2016). However, little is known regarding the composition of SB messages in the context of European soccer, considering the majority of the research is circumscribed to the Australian gambling sector and focused on mostly unfamiliar sports in Europe (i.e. rugby league and Australian football).

The present study examines SB advertisements $(\mathrm{N}=102)$ from the $\mathrm{UK}$ in order to understand how themes from SB narratives shape and structure betting behaviour. The study follows a Grounded Theory (GT) approach to inductively assess the main themes and narratives in SB advertisements. In the Method section, the GT procedure is described in detail, and explains how the notion of "control" emerged in second cycle coding as the core narrative category. Control has been previously proposed by Deans et al. (2016) as the third most prevalent theme in SB narratives (19\% of the adverts), yet narratives featuring the idea of control are currently unaddressed by responsible gambling communication regulations. The present paper makes the case of control as the core theme that structures SB advertising in the $\mathrm{UK}$, and puts forward a theoretical model that integrates into a single narrative strategy many of the individually identified themes in the previous literature. Therefore, the next section introduces relevant context for the concept of control in gambling.

\section{Control perception in gambling}

Some of the factors often cited to explain gamblers' behaviour involve cognitive distortions, and beliefs that make gamblers misperceive (typically overestimate) their control over their gambles (e.g., Ejova, Delfabbro, \& Navarro, 2015; Griffiths, 1994; Moore \& Ohtsuka, 1999). Among cognitive distortions, the illusion of control (Langer, 1975) has traditionally been considered to have a large influence on gambling behaviour, and also in the development of gambling disorder (GD) (Stark, 2014). The illusion of control was first defined as "an expectancy of a personal success probability inappropriately higher than the objective probability would warrant" (Langer, 1975, p. 313). Applied to gambling, gamblers overestimate their control over uncontrollable (or minimally controllable) events and build causal relationships between their behaviour and the outcome of such events.

According to Langer (1975), perceived skill factors introduced into chance situations cause an illusion of control. This finding is critical in understanding control-related distortions in gambling. In experiments where gamblers have been presented with pseudo-controlling situations (e.g., picking their own number in a lottery; Burger, 1991) or bogus artefacts misconstrued as control-enhancers (e.g., using a reel-stopping device in a video lottery terminal game; Ladouceur \& Sévigny, 2005), it has been demonstrated that gamblers 
consistently prefer these options when presented even if these actions have no instrumental impact on gambling outcomes. In other contexts, researchers have also found that people tend to exaggerate the benefits of devices that enhance the illusion of control, and fail to detect that such devices do not offer any advantage in gambling outcomes (Davis \& Kottemann, 1994). Some of the theories proposed to explain such behaviour include the desire to have control over extrinsic rewards (Burger \& Schnerring, 1982) and the need of gamblers to retain control over their actions, internalising the locus of control of (in theory) externally caused outcomes (Hong \& Chiu, 1988).

The theory of illusory control was later nuanced in a new model proposed by Rothbaum, Weisz and Snyder (1982). In their model, perceived control is a two-process dynamic that entails a primary and a secondary control strategy. Primary control occurs when individuals "attempt to change the world so if fits the self's needs" $(1982$, p. 8). However, when this change is not possible, individuals adjust to resistances and develop a secondary control strategy that consists in attempting to "fit in with the world" (1982, p. 8). Primary and secondary control strategies do not exclude each other, and typically it is a matter of emphasis how individuals shift from one to another. Later research has theorised that there is a functional primacy of primary over secondary control mechanisms (Heckhausen \& Schulz, 1995). According to this view, when individuals fail to change the world to fit their needs, they resort to secondary control strategies to protect their own perception of control, and which are internal processes within each individual. A major mechanism of secondary control is what Rothbaum and colleagues (1982) referred to as predictive control. Predictive control could, theoretically, play a role in SB behaviour, because when individuals feel uneasy regarding an uncontrollable event, they can reduce their discomfort by making predictions about that event, although no empirical evidence is available in this regard.

It has also been shown that when individuals with GD perform longer tasks, their illusion of control is bigger and their ability to discriminate non-contingent from contingent actionoutcome tasks is smaller than in controls (Perales, Navas, Ruiz de Lara, Maldonado et al., 2016). Orgaz et al. (2013) previously found results that indicated a stronger illusion of control among individuals with GD. In this regard, Cowley and colleagues (2015) noted that people that felt their illusion of control was threatened by a bet lost were more likely to construct their retrospective evaluation of their gambling activity by giving a disproportionate importance to those bets in which they won, whereas participants with low illusory control beliefs (or those who have won) were more likely to re-tell their own gambling story considering the final outcome as baseline for the evaluation. Especially relevant for SB is the finding that individuals with GD and higher illusion of control become overconfident and often accept less favourable bets at equal rates which leads them to greater losses than other bettors without GD (Goodie, 2005). 


\section{Method}

\section{Data collection}

The sample comprised soccer betting advertisements produced for television broadcast in the United Kingdom (UK) and uploaded by bookmaking brands to their official British YouTube channels. An initial sample (N=83) comprised adverts uploaded from June 2014 to June 2016. The data from this period were analysed starting in June 2016, while the authors continued to collect new SB advertisements and compare them with the preliminary data from the initial sample. This process was discontinued in December 2016, producing the final sample $(\mathrm{N}=102)$. The two-step data sampling was inspired by Strauss and Corbin (1998), who recommend the simultaneous collection and analysis of data until reaching "saturation", the moment when "no new information seems to emerge during coding" (p. 136). Fundamentally, adverts from the first sample were used to build from scratch a theoretical model "grounded" in the data. After refining the theory, it was tested against new advertisements to examine whether (i) the theory had predictive value to analyse future adverts; (ii) saturation was indeed achieved and no further components were needed to be considered for inclusion in the theory.

Advertisements were gathered from 21 SB brands ${ }^{1}$ licensed to legally operate within the UK. These brands were selected based on their popularity on specialised internet forums, profit rankings in the gambling trade journal iGaming Business, and their presence as sponsors, official partners, and/or regular advertisers in sport events. According to William Hill's Annual Report (2016), three companies (Ladbrokes \& Coral, William Hill, and Betfred) account for $87 \%$ of the British sports betting retail market. As to the online betting market, $84 \%$ of it is dominated by only five companies (Paddy Power, Bet365, William Hill, Ladbrokes \& Coral, and Sky Bet). All these gaming operators' adverts are among the 21 selected brands for the present study. Thus, the sample here is likely to represent more than $90 \%$ of the market share in the country.

The selected advertisements met the following inclusion criteria: (i) soccer was the only or main sport featured in the advert; (ii) the adverts had to have a televisual and temporal format (between 20 and 60 seconds duration). This latter inclusion criterion excluded madefor-internet promotions that typically allow informal shooting or discussion-like videos including tipsters sponsoring a brand. Also, longer advertisements were excluded because they were unlikely to have been shown on television; (iii) the advertisements had to mention online $\mathrm{SB}$, excluding rare occurrences where only offline SB was addressed.

In order to contrast if adverts from YouTube channels accurately represented the actual advertisements shown on television, a third sample of nine Premier League (shown on Sky Sports) and Union of European Football Associations (UEFA) Champions League (shown on 
BT Sport) soccer matches from 2015/2016 season were recorded. Adverts from commercial breaks before, during, and after each match were extracted and compared with the existing database. The results confirmed that all of the adverts shown on television were already available, or were made available soon after, on the YouTube channels. Additionally, brands from electronic banners around the pitch and sponsoring shirts were identified to make sure every bookmaker was represented in the final sample.

\section{Procedure}

The analytical approach to data selected was grounded theory (GT). GT research methods comprise "systematic, yet flexible guidelines for collecting and analysing qualitative data to construct theories 'grounded' in the data themselves" (Charmaz, 2006, p. 2). GT is a fundamentally inductive perspective that seeks to examine data in a holistic manner and with no pre-existing theoretical framework. In some scholarly traditions, GT has been inherently associated with conversational and observational analysis, prioritising data deriving from interviews. However, GT has been argued to be a valid method for any data format (Charmaz, 2006).

GT is often conducted through immersion in the dataset, with repeated cycles of data analysis rather than linear coding (Saldaña, 2009). The short duration of each unit of analysis in the present study (typically around 30 seconds) favoured such cyclical coding. The coding procedure was structured in two cyclical stages (namely first and second cycle coding methods) following some of the coding categories proposed by Saldaña (2009). In the first cycle, the initial sample was examined using holistic coding, an exploratory method to grasp basic rather than line-by-line topics, extracting paradigmatic illustrations by in vivo coding. Codes were themed as broadly as possible to allow for posterior refinement. Following discussion between the authors, all the themes that emerged in the first cycle, and using focused coding as a way to merge the most salient themes, it was decided to focus on the analysis of the broad concept of control, which at this point re-structured the aim of the study and became its "central or core category" (Strauss \& Corbin, 1998, p. 146).

Later, with control as the underlying theoretical focus, all the adverts were newly analysed several times by the first author. In this second round of analysis, again first cycle methods were employed. Structural coding was then used, which is a preliminary way of coding data but with a specific research question in mind, in this case, how advertisements constructed the idea of bettors' control. Due to this method, data that were not primarily linked to the idea of control were then re-thematised as part of its construction. In parallel, in vivo coding was also utilised to extract paradigmatic expressions that conveyed such ideas. Finally, after discussing the results from the second round with the other authors, a theoretical coding was performed, 
which resulted in the integration of all the themes around the core category. In the following section, results stemming from these coding cycles are presented.

\section{Results and preliminary discussion}

The initial sample was first analysed following holistic coding. The coding resulted in a preliminary list of 36 themes. After the authors had discussed the findings, a more focused coding was conducted to refine each theme and converge them into broader and more abstract categories. The final list of 15 themes, ranked by their frequency, is shown in Table 1 wherein themes are followed by a brief description and an example to illustrate how they were presented in a specific advert.

\section{TABLE 1 NEAR HERE}

Many of the topics emerging from the adverts appeared to be constructing an image of the bettors as individuals willing for control in an inherently uncontrollable environment. Brands generally offered control, and thus, a bigger winning probability, while new features introduced by adverts appeared to be useful tools to enhance that control. Consequently, a new round of first cycle coding was conducted. This time, themes in the adverts were specifically examined (i.e., structured coding) regarding their properties to increase perceived control in bettors. During the coding, themes were no longer considered individually but as a whole, and authors attempted to integrate them into a broader narrative.

The result of this process was the integration of most of the themes to build a single narrative of control that could theoretically be plausible and true for every advert. The themes included here were those ranked in number $1,2,3,4,5,6,7,8,9,11$, and 13 . The authors were not able to integrate themes ranked 10 (Glamour), 12 (True fan), 14 (Rational vs. Emotional), and 15 (Escape) into the single narrative of control theorised and were therefore discarded. The remaining themes were used to build a theory that posed that most individual themes in SB advertising in the UK could be better understood as serving a bigger narrative of control, which was considered the core narrative strategy of SB.

This theory was sub-divided into two propositions or hypotheses. The first hypothesis (the control versus risk balance) proposes that Themes 1 (Fun), 2 (Humour), 3 (Friendship), 4 (Free money), and 7 (Celebrities) work in conjunction as risk-lowering strategies in SB adverts, while Themes 9 (Masculinity), 11 (Analysis and knowledge), and 13 (Experience) serve as control-enhancing mechanisms. The second hypothesis (the technological substitution) poses that Themes ranked in number 5 (New functionalities), 6 (Ubiquity), and 8 (Ease of access) can be better understood as a single narrative that enhances bettors' perception of control by 
substituting bet prediction for platform/device control. This theory, which is elaborated in the next section, was later tested against newly collected adverts until it was deemed adequate.

\section{Theory Building}

\section{The control versus risk balance hypothesis}

The present paper theorises that control in SB narratives is built around two complementary advertising strategies. On the one hand, advertising emphasizes attributes of SB that enhance the perceived control of bettors. On the other hand, advertising also emphasizes attributes of SB that reduce the perceived risk of betting. The sought-after combination for bookmakers would be then to present products perceived as featuring the highest possible control and the lowest possible risk. Figure 1 provides an overview of the taxonomy of SB depending upon the balance between control enhancement and risk reduction.

A narrative based on attributes from the left lower quadrant would be contrary to intuition, since products perceived as offering high risks with low control over them will not be attractive for bettors. Right lower quadrant offers theoretically an interesting possibility. The combination of high risk but also high control could be appropriate for sensation seekers. A bettor could decide to engage in very risky bets if the outcome compensates the risk taken, for instance in the form of an improbable huge prize. However, no SB advertiser was found to follow this logic in the sample selected.

Both positions in the upper half deal with low risk situations. Low risk and low control conditions (upper left) were frequently employed in SB advertising. References to fun and excitement do not necessarily draw on enhanced controls attributes but accentuate the lack of negative consequences of losing a bet. More frequently, though, bookmakers position their brands in the upper right quadrant, promoting low risk products in control-enhancing conditions. Framing messages within the upper half ideally can permit bettors to see themselves as performing a low risk endeavour with some degree of personal control over it. However, in the event of a lost bet, the advertising narrative opens the possibility for bettors to transition from right to left, exchanging the reward content from extrinsic to intrinsic (that is, from money to fun). Constantly within the low risk quadrants, bettors remain as winners at all time, conveniently shifting from money to fun prizes.

\section{FIGURE 1 NEAR HERE}

Themes re-align well in this dual strategy. On the one hand, the risk-lowering strategy involves narratives that include themes such as free money, friendship, fun/excitement, humour, and 
celebrity use. Considered as a whole, all these themes contribute to the perception of SB as a risk-free or low risk activity.

Money-related promotions - e.g. money back, price guarantee, free bet- add to the idea that SB has no negative consequences and that mistakes can often be undone. Friendship and camaraderie create a familiar context of comfort and security in which behaviour is reinforced by imitation. Many adverts portray friends discussing SB options while enjoying watching sport together. Humour can also be understood as a risk-lowering tactic. Humorous gags and scenarios in advertisements, widely used by bookmakers, can convey the impression that SB regularly happens in a context of entertainment, downplaying the importance of bad betting decisions. Humour, when associated with friendship, also strengthens the notion that having fun with friends is the ultimate reward of SB. In this regard, fun and entertainment are not isolated themes but work in conjunction with humour and friendship to construct overarching narratives of safety and comfort that encourage risk-free betting.

Similarly, the use of celebrities also aligns with risk-lowering strategies. Among other advantages, well known faces are considered to reduce the uncertainty in the consumption of new products and transfer their credibility and trustworthiness to the brand. Also, brands willing to pay for the endorsement of popular sports celebrities establish their financial muscle and increase their perceived capacity to pay off winning clients. Secondly, sports celebrities serve a dual purpose in the risk-lowering control enhancement strategy. By definition, becoming a professional athlete means beating the odds. The lives of many sport celebrities represent a story in which an immensely low probability (becoming a sports star) has been turned into a story of success by means of continual skilled training (i.e., control).

On the other hand, the control-enhancing strategy includes themes such as data analysis and sports knowledge, experience, and masculinity. Data analysis and sports knowledge act as control-enhancing mechanisms. SB is presented as an activity that can be mastered with enough preparation and skills. Knowledge assists bettors by informing their decisions, and to that effect, bookmakers provide their clients with background information, a wealth of statistics, and news stories concerning the teams and players in the games. Following this logic, unpredictable events are turned into predictable ones, and amendments for lost bets can be made through better preparation in the future. Adverts that target older adults include the experience component wherein older characters make use of their accumulated sports knowledge over the years to beat younger bettors.

Another theme involved in the enhancement of control is masculinity. Although not explicitly mentioned in any advert, masculinity is an underlying theme in many of them. Masculinity aligns with a representation of decisive and courageous behaviour. In some instances, such as adverts that show characters deciding whether to place a risky bet, 
masculinity gives them a boost of confidence to accept the challenge in the form of authoritarian thinking or recklessness.

Against the backdrop of risk-reduction and control-enhancing narratives, new technological features play a pivotal role. The opportunity to follow in-play SB through live audio or video feeds, advertised by a number of bookmakers, transforms the bettor into an eyewitness who does not need to rely on others to know what is happening, even in situations where a television screen is not available. Features such as tracking platforms or text alerts add to the idea of surveillance that bettors can exert over their bets, reducing the risk involved while increasing the control. Broadly speaking, SB advertising appears to have found a way to reduce the inherent perceived risk by reducing the distance (both physical and emotional) between the bettor and the sport event, with expressions in the adverts such as "it's like being there". New functionalities such as cash out, exchange, or accumulators are claimed as providing bettors more control over their bets. Technological innovation introduces a changing context in which general attributes such as speed, ease of use, ubiquity, and accessibility are essential components of contemporary SB.

\section{The technological substitution hypothesis}

As the second proposition of the narrative of control in SB adverts, the present paper further theorises that SB online platforms and devices are configured in SB advertising as control enhancers, and furthermore, that the ability to predict the outcome of a sport event is substituted by the ability to use such platforms and devices. Figure 2 proposes via a three-step diagram such substitution. Step II and III are readily observable in the adverts, while Step I is implied as the antecedent.

\section{FIGURE 2 NEAR HERE}

Step I condenses the baseline narrative for control in SB advertising. Here, the difficulty of a bet lies in the intersection between the difficulty of predicting an event and the ability to predict it. More probable events are easier to predict, and similarly, stronger predictive capacities are more likely to be able to predict more complex events. A low ability to predict combined with a difficult bet will result in a lost bet; conversely, easier bets accompanied by better predictive skills will result in a won bet. Naturally, advertising will exaggerate the control/skill components in the balance in order to sell the idea that winning a bet is more likely than it actually is, while the brand advertised will typically be presented as a control enhancer tool.

However, in SB advertising, the terms by which enhancement of control is claimed are misleading. The theory poses that the baseline SB narrative - balance between difficulty of 
predicting an event and skill to bet- is transformed in SB advertisements in favour of a narrative that thinks of SB as a balance between the difficulty of using a SB platform and the skill to use. In other words, the outcome of a bet is no longer as determined by the skill to predict future events as by the ability to control the technology to bet (i.e., platforms and devices).

The transformation can be analytically divided into two steps. In Step II, there is a role activation of sport bettors. Control enhancement depends greatly on the internalisation of the locus of control, but bettors can hardly think that they have any active role in a sport game in which they do not participate. SB advertising tackles this issue by transforming the perception of some elements. Adverts repeatedly claim that games happen in the bettors' screen. The platform/device becomes the field of play, and the interaction with the device is where the game happens. Some adverts represent bettors as football players or managers in the game they are betting on.

Once the role of the bettors has been activated, Step III shows the resulting scenario. If bettors accept the mental configuration proposed by SB advertisers, then the balance between a bet lost and won depends on the ability to control a platform and the difficulty of doing it. Quicker and easier to use platforms will have a direct effect on more controlled and easier bets, and naturally, bookmakers position their products along those lines. If adverts parallel the difficulty of predicting the outcome of a sporting event with the difficulty of placing a bet on that event, bettors can exert direct control over the outcome of their bets by using quicker and easier technologies.

\section{General discussion}

The present study sought to build a comprehensive theory of control in sports betting (SB) advertising. Departing partially from previous literature in the field where themes are presented as separate advert narratives, the data gathered from a sample of 102 British SB advertisements were analysed in order to hypothesise a single core narrative that integrated most individual themes from various narratives. Using first and second cycle methods from grounded theory (GT), the paper argues that SB adverts can be understood in terms of a narrative that seeks to reduce the perceived risk of betting while enhancing the perceived control of bettors.

Risk-lowering themes such as those employed in the narratives analysed here make sense from a communication perspective. The gradual moral acceptance and normalisation of gambling in the UK since the 2005 Gambling Act 2005, progressively distancing from previous negative connotations (Parke, Harris, Parke, Rigbye, \& Blaszczynski, 2014), helps explain the emphasis of advertisers in those themes. Furthermore, risk reduction is a common goal of 
advertising in any market sector (Boshoff, 2002). Displays in adverts of friendship and camaraderie, for instance, could add to the myth of gambling as a harmless activity if done publicly, as previously noted by Deans et al. (2016) when comparing gambling and alcohol advertisements. Other scholars have already posed the need for free money inducement regulation (Hing et al., 2016), and celebrity endorsement is widely used across markets. However, the attraction of children and young adults to elite sports stars might make advisable to limit the belief distortions around control and risk-free SB that some narratives appear to enact.

Along with risk-reducing components, the theory anticipates a disproportionate emphasis on control-enhancing elements in the narratives. SB advertisements have increased in recent years their focus on exotic bets (e.g., number of corners in the next 15 minutes) and complex combinations of bets (e.g., accumulators consisting of multiple bets) (Gainsbury \& Russell, 2015). Yet, the outcome of such bets is often difficult to calculate and regularly involves a higher loss expectancy (Hing et al., 2016). Bettors typically resort to heuristics to process information (e.g., representativeness heuristics) which can lead to a distorted perception and biased judgement (Griffiths, 1994; Newall, 2015). Narratives that enhance control, combined with new technological tools that supposedly aid that process, are plausible, theoretically, to magnify bettors' perceived control, persuading them to bet more recklessly.

Generally, sports bettors do not exert primary control over the outcome of their bets, excluding those instances in which they bet on their own games (a practice typically forbidden) or when they participate in match-fixing and directly influence game development (Van Rompuy \& Asser Institute, 2015). Following the two-step theory of control (Rothbaum et al., 1982), bettors would resort to secondary control strategies to regain some sense of internal control over their bets, for example, predicting game outcomes that are out of their reach. However, according to the theory of SB advertising proposed in the present paper, advertisers appear to be transforming perception of secondary control back into primary control. The constant mentions in adverts to the platforms as the place where the games are played, and the activation of the role of bettors, internalising their locus of control, could be adding to the illusion of SB as a primary control tool of sports action. Conceivably, primary perception of control is far more powerful than secondary control, and from an advertising point of view, more persuasive.

Additionally, higher perceived control sensation could be further prompted by new SB technological affordances. Online betting imagery differs greatly from other forms of gambling such as lottery playing. Bettors are generally not encouraged to seek for a once-in-a-lifetime strike of luck but to persevere in their SB to make small but frequent amounts of additional money. SB imagery typically entails a dynamic of multiple repetitions over time of small or moderate bets. Frequent wins are known to induce the sensation of control rather than 
infrequent wins (Letarte, Ladouceur, \& Mayrand, 1986), an association that appears to be logical. However, as noted by Binde (2009), small and frequent wins do not necessarily translate into a net win, and many bettors, especially problem gamblers, might overestimate the overall money won while underestimate their losses (Griffiths, 1994). All things considered, the interaction of frequent wins over time with the primary perception of control, could provoke bettors to think about themselves as winners, an identity trait rather than a transitory condition. That characterisation would be consistent with sports world symbolism (Deans et al., 2017), and further backed by masculinity and knowledge values of perceived empowerment.

The present study is not without its limitations. The relatively small number of adverts comprising the sample (although larger than many of previously published studies), and the short period of analysis (2014-2016) was intended to serve analytical purposes. Consequently, it is not necessarily representative of the larger evolution of SB advertising over a longer time period. Also, SB here is focused on its most characteristic type, soccer, although other sports and betting practices such as horse and dog racing are also popular in the UK. Therefore, the particular sports betting ecosystem in Britain does not necessarily mean the results are generalizable to other countries.

\section{Implications and conclusions}

If, as contended here, SB advertising continues to emphasize those aspects that make gambling be perceived as a more controllable activity, new technological developments that align with that core concept might be favoured by bookmakers. An increased gamification of SB appears to be likely in such a scenario. By turning gambling dynamics into game dynamics, SB can arguably incorporate these characteristics: (i) more engaging and attention-demanding products, with bettors required to perform composite complex actions and calculations; (ii) as bettors adopt a more active role, betting outcomes will be more likely be misconstrued as results of that role; (iii) the positive connotations of playing (e.g., healthy, fun) will help to reduce the associated risks of SB and focus on its entertainment value; and (iv) as bettors become players, the juxtaposition and confusion of roles of those in the field and those betting in their devices could be intensified. The convergence already in motion of gambling and gaming products such as SB, poker, and social games testifies to that effect (Cassidy, 2013; Lopez-Gonzalez \& Griffiths, 2016b). Interestingly, a study examining fantasy sports - arguably a seminal form of gamified SB - found that players that were allowed higher levels of customisation in the platform, reported higher winning expectancy and were more likely to believe that they could control the outcome, even when such customisation had no actual effect on it (Kwak, Lee, \& Mahan III, 2013). Business reports from betting operators coincide in highlighting gamification as a main innovation strategy in SB (Betradar, 2016). 
To counterbalance such evolution, regulation will need to play an increasingly prominent role. Currently, advertisements conveying narratives that exaggerate control are not illegal. In a help note published in the UK by the Committee of Advertising Practice (CAP) and the Broadcast Committee of Advertising Practice (BCAP) entitled Guidance on the rules for gambling advertisements, it was stated that marketing communications must not "suggest that gambling can enhance personal qualities, for example, that it can improve self-image or self-esteem, or is a way to gain control, superiority, recognition or admiration" (CAP \& BCAP, 2014, p. 7). However, the concept of control is vague in this definition, and arguably does not refer to the term as it has been construed in the present paper. Legal frameworks are straightforward when regulating elemental components of advertising (e.g., inclusion of responsible gambling messages, age limitations, fine print) but struggle to assess (and censor, if necessary) more nuanced components such as narrative make-ups. In this regard, it is worth keeping an eye on the development of latent narratives such as those of control to ascertain whether they have a negative impact on the conceptualisation and shaping of SB behaviour in bettors' minds.

Notes

${ }^{1}$ The SB brands used in this study were: Betfair, Bet365, William Hill, Skybet, Marathonbet, Titanbet, 888 Sport, Unibet, Betvictor, Ladbrokes, Coral, Paddy Power, Bet-at-home, Betsafe, Betfred, NetBet, Sun Bets, 1oBet, Dafabet, 188 Bet, and Betway.

\section{References}

Betradar. (2016). Live sports betting. In-play soccer games. The gamification of your live betting portfolio. Retrieved January 5, 2017, from https://www.betradar.com/wpcontent/uploads/sites/4/2016/o1/betradar_virtual_gaming_brochure.pdf

Binde, P. (2009). "You could become a millionaire": Truth, deception, and imagination in gambling advertising. In S. Kingma (Ed.), Global gambling: Cultural perspectives on gambling organizations (pp. 171-194). London: Routledge.

Binde, P. (2014a). Gambling advertising: A critical research review. London.

Binde, P. (2014b). Gambling in Sweden: The cultural and socio-political context. Addiction, 109, 193-198. http://doi.org/10.1111/add.12103

Boshoff, C. (2002). Service advertising. Journal of Service Research, 4(4), 290-298. http://doi.org/10.1177/1094670502004004006

Burger, J. M. (1991). The effects of desire for control in situations with chance-determined outcomes: Gambling behavior in lotto and bingo players. Journal of Research in Personality, 25(2), 196-204. http://doi.org/10.1016/o092-6566(91)90015-I 
Burger, J. M., \& Schnerring, D. A. (1982). The effects of desire for control and extrinsic rewards on the illusion of control and gambling. Motivation and Emotion, 6(4), 329-335. http://doi.org/10.1007/BFoo998189

CAP, \& BCAP. (2014). Guidance on the rules for gambling advertisements. London: Committee of Advertising Practice and Broadcast Committee of Advertising Practice.

Cassidy, R. (2013). Partial convergence. Social gaming and real-money gambling. In R. Cassidy, A. Pisac, \& C. Loussouarn (Eds.), Qualitative research on gambling. Exploring the production and consumption of risk (pp. 74-91). New York: Routledge.

Charmaz, K. (2006). Constructing grounded theory: A practical guide through qualitative analysis. Thousand Oaks, CA: Sage.

Cowley, E., Briley, D. A., \& Farrell, C. (2015). How do gamblers maintain an illusion of control? Journal of Business Research, 68(10), 2181-2188. http://doi.org/10.1016/j.jbusres.2015.03.018

Crawford, G. (2004). Consuming sport: fans, sport and culture. London: Routledge.

Davis, F. D., \& Kottemann, J. E. (1994). User perceptions of decision support effectiveness: Two production planning experiments. Decision Sciences, 25(1), 57-76. http://doi.org/10.1111/j.1540-5915.1994.tboo516.x

Deans, E. G., Thomas, S. L., Daube, M., \& Derevensky, J. (2017). The role of peer influences on the normalisation of sports wagering: a qualitative study of Australian men. Addiction Research \& Theory, 25, 103-113. http://doi.org/10.1080/16066359.2016.1205042

Deans, E. G., Thomas, S. L., Daube, M., Derevensky, J., \& Gordon, R. (2016). Creating symbolic cultures of consumption: an analysis of the content of sports wagering advertisements in Australia. BMC Public Health, 16(1), 208. http://doi.org/10.1186/s12889-016-2849-8

Deans, E. G., Thomas, S. L., Derevensky, J., \& Daube, M. (2017). The influence of marketing on the sports betting attitudes and consumption behaviours of young men: implications for harm reduction and prevention strategies. Harm Reduction Journal, 14(1), 5. http://doi.org/10.1186/s12954-017-0131-8

Ejova, A., Delfabbro, P. H., \& Navarro, D. J. (2015). Erroneous gambling-related beliefs as illusions of primary and secondary control: A confirmatory factor analysis. Journal of Gambling Studies, 31(1), 133-16o. http://doi.org/10.1007/s10899-013-9402-9

European Commission. (2011). On-line gambling in the internal market (Green paper COM 2011). Brussels. Retrieved from

http://ec.europa.eu/internal_market/consultations/docs/2011/online_gambling/com2 011_128_en.pdf

European Commission. (2014). Recommendation on principles for the protection of consumers and players of online gambling services and for the prevention of minors 
from gambling online (C(2014) 4630/3). Brussels.

Gainsbury, S., Delfabbro, P., King, D. L., \& Hing, N. (2016). An exploratory study of gambling operators' use of social media and the latent messages conveyed. Journal of Gambling Studies, 32(1), 125-141. http://doi.org/10.1007/s10899-015-9525-2

Gainsbury, S., \& Russell, A. (2015). Betting patterns for sports and races: A longitudinal analysis of online wagering in Australia. Journal of Gambling Studies, 31(1), 17-32. http://doi.org/10.1007/s10899-013-9415-4

Goodie, A. S. (2005). The role of perceived control and overconfidence in pathological gambling. Journal of Gambling Studies, 21(4), 481-502. http://doi.org/10.1007/s10899-005-5559-1

Gordon, R., Gurrieri, L., \& Chapman, M. (2015). Broadening an understanding of problem gambling: The lifestyle consumption community of sports betting. Journal of Business Research, 68(10), 2164-2172. http://doi.org/10.1016/j.jbusres.2015.03.016

Griffiths, M. D. (1994). The role of cognitive bias and skill in fruit machine gambling. British Journal of Psychology, 85, 351-369.

Griffiths, M. D. (2005). Does gambling advertising contribute to problem gambling? International Journal of Mental Health \& Addiction, 3, 15-25.

Hanss, D., Mentzoni, R. A., Griffiths, M. D., \& Pallesen, S. (2015). The impact of gambling advertising: Problem gamblers report stronger impacts on involvement, knowledge, and awareness than recreational gamblers. Psychology of Addictive Behaviors, 29(2), 483491. http://doi.org/10.1037/adbooooo62

Heckhausen, J., \& Schulz, R. (1995). A life-span theory of control. Psychological Review, 102(2), 284-304.

Hing, N., Russell, A. M. T., Lamont, M., \& Vitartas, P. (2017). Bet anywhere, anytime: An analysis of internet sports bettors' responses to gambling promotions during sports broadcasts by problem gambling severity. Journal of Gambling Studies. http://doi.org/10.1007/s10899-017-9671-9

Hing, N., Sproston, K., Brook, K., \& Brading, R. (2016). The structural features of sports and race betting inducements: Issues for harm minimisation and consumer protection. Journal of Gambling Studies. http://doi.org/10.1007/s10899-016-9642-6

Hing, N., Vitartas, P., \& Lamont, M. (2014). Promotion of gambling and live betting odds during televised sport: Influences on gambling participation and problem gambling. Lismore: Centre for Gambling Education and Research.

Hirschman, E. C. (1988). The ideology of consumption : A structural-syntactical analysis of "Dallas” and “ Dynasty ." Journal of Consumer Research, 15(December), 344-59.

Hong, Y.-Y., \& Chiu, C.-Y. (1988). Sex, locus of control, and illusion of control in Hong Kong as correlates of gambling involvement. The Journal of Social Psychology, 128(5), 667- 
673. http://doi.org/10.1080/o0224545.1988.9922920

Korn, D., Hurson, T., \& Reynolds, J. (2005). Commercial gambling advertising: Possible impact on youth knowledge, attitudes, beliefs, and behavioural intentions. Guelph: Ontario Problem Gambling Research Centre.

Kwak, D. H., Lee, J. S., \& Mahan III, J. E. (2013). Ad-evoked illusory judgments in Fantasy Sports participation: Effects of customization level and expert information. Journal of Sport Management, 27(5), 393-406.

Ladouceur, R., \& Sévigny, S. (2005). Structural characteristics of video lotteries: Effects of a stopping device on illusion of control and gambling persistence. Journal of Gambling Studies, 21(2), 117-131. http://doi.org/10.1007/s10899-005-3028-5

Lamont, M., Hing, N., \& Vitartas, P. (2016). Affective response to gambling promotions during televised sport: A qualitative analysis. Sport Management Review, 19(3), 319-331. http://doi.org/10.1016/j.smr.2015.06.002

Langer, E. (1975). The illusion of control. Journal of Personality and Social Psychology, 32(2), 311-328. http://doi.org/10.1037/oo22-3514.32.2.311

Letarte, A., Ladouceur, R., \& Mayrand, M. (1986). Primary and secondary illusory control and risk-taking in gambling (Roulette). Psychological Reports, 58(1), 299-302. http://doi.org/10.2466/pro.1986.58.1.299

Lopez-Gonzalez, H., \& Griffiths, M. D. (2016a). Is European online gambling regulation adequately addressing in-play betting advertising? Gaming Law Review and Economics, 2o(6), 495-503. http://doi.org/10.1089/glre.2016.2064

Lopez-Gonzalez, H., \& Griffiths, M. D. (2016b). Understanding the convergence of online sports betting markets. International Review for the Sociology of Sport. http://doi.org/doi:10.1177/1012690216680602

Lopez-Gonzalez, H., Estévez, A., \& Griffiths, M. D. (2017). Marketing and advertising online sports betting: A problem gambling perspective. Journal of Sport \& Social Issues, 41(3), 256-272. http://doi.org/https://doi.org/10.1177/o193723517705545

McMullan, J. L., \& Miller, D. (2008). All in! The commercial advertising of offshore gambling on television. Journal of Gambling Issues, 22, 230-251. http://doi.org/10.4309/jgi.2008.22.6

McMullan, J. L., \& Miller, D. (2009). Wins, winning and winners: The commercial advertising of lottery gambling. Journal of Gambling Studies, 25, 273-295. http://doi.org/10.1007/s10899-009-9120-5

Milner, L., Hing, N., Vitartas, P., \& Lamont, M. (2013). Embedded gambling promotion in Australian football broadcasts: An exploratory study. Communication Politics \& Culture, $46,177-198$.

Milner, L., \& Nuske, E. (2012). Laying your cards on the table: representations of gambling in 
the media. Australian Journal of Communication, 39(2), 83-99.

Monaghan, S., Derevensky, J., \& Sklar, A. (2008). Impact of gambling advertisements and marketing on children and adolescents: Policy recommendations to minimise harm. Journal of Gambling Issues, 22, 252-274. http://doi.org/10.4309/jgi.2008.22.7

Moore, S. M., \& Ohtsuka, K. (1999). Beliefs about control over gambling among young people, and their relation to problem gambling. Psychology of Addictive Behaviors. http://doi.org/10.1037/0893-164X.13.4.339

Newall, P. W. S. (2015). How bookies make your money. Judgment and Decision Making, $10(3), 225-231$.

Orgaz, C., Estévez, A., \& Matute, H. (2013). Pathological gamblers are more vulnerable to the illusion of control in a standard associative learning task. Frontiers in Psychology, 4, 306. http://doi.org/10.3389/fpsyg.2013.00306

Parke, A., Harris, A., Parke, J., Rigbye, J., \& Blaszczynski, A. (2014). Responsible marketing and advertising in gambling: A critical review. Journal of Gambling Business and Economics, 8(3), 21-35.

Perales, J., Navas, J., Ruiz de Lara, C., Maldonado, A., \& Catena, A. (2016). Causal learning in gambling disorder: Beyond the illusion of control. Journal of Gambling Studies, doi:10.1007/s10899-016-9634-6

Rothbaum, F., Weisz, J., \& Snyder, S. (1982). Changing the world and changing the self: A twoprocess model of perceived control. Journal of Personality and Social Psychology, 42(1), $5-37$.

Saldaña, J. (2009). The coding manual for qualitative researchers. Thousand Oaks, CA: Sage.

Sklar, A., \& Derevensky, J. L. (2011). Way to play: Analyzing gambling ads for their appeal to underage youth. Canadian Journal of Communication, 35(4), 533-554.

Sproston, K., Hanley, C., Brook, K., Hing, N., \& Gainsbury, S. (2015). Marketing of sports betting and racing. Melbourne: Gambling Research Australia.

Stark, S. M. (2014). The dynamics of control: Exploring sense of control, illusion of control, and gambling self-efficacy among frequent gamblers (doctoral thesis). University of Toronto, Toronto, Canada.

Strauss, A., \& Corbin, J. M. (1998). Basics of qualitative research: Techniques and procedures for developing grounded theory (2nd ed.). Newbury Park, CA: Sage.

Thomas, S. (2014). Parents and adolescents discuss gambling advertising: A qualitative study. Melbourne: Victorian Responsible Gambling Foundation.

Thomas, S., Bestman, A., Pitt, H., Deans, E., Randle, M., Stoneham, M., \& Daube, M. (2015). The marketing of wagering on social media: An analysis of promotional content on YouTube, Twitter and Facebook. Victoria, Australia: Victorian Responsible Gambling Foundation. 